\title{
A New Concept: $\mathrm{A} \beta_{1-42}$ Generates a Hyperfunctional Proteolytic NCX3 Fragment That Delays Caspase-12 Activation and Neuronal Death
}

\author{
Anna Pannaccione, ${ }^{1 \star}$ Agnese Secondo, ${ }^{1 *}$ Pasquale Molinaro, ${ }^{1 \star}$ Carla D’Avanzo, ${ }^{1}$ Maria Cantile, ${ }^{1}$ Alba Esposito,${ }^{1}$ \\ Francesca Boscia, ${ }^{1}$ Antonella Scorziello, ${ }^{1}$ Rossana Sirabella, ${ }^{2}$ Gianfranco Di Renzo, ${ }^{1}$ and Lucio Annunziato ${ }^{1,2}$ \\ ${ }^{1}$ Division of Pharmacology, Department of Neuroscience, National Institute of Neuroscience, School of Medicine, "Federico II" University of Naples, 80131 \\ Naples, Italy, and ${ }^{2}$ Fondazione Istituto Di Ricovero e Cura a Carattere Scientifico SDN, 80143 Naples, Italy
}

Although the amyloid- $\beta_{1-42}\left(\mathrm{~A} \beta_{1-42}\right)$ peptide involved in Alzheimer's disease is known to cause a dysregulation of intracellular Ca ${ }^{2+}$ homeostasis, its molecular mechanisms still remain unclear. We report that the extracellular-dependent early increase (30 min) in intracellular calcium concentration $\left(\left[\mathrm{Ca}^{2+}\right]_{\mathrm{i}}\right)$, following $\mathrm{A} \beta_{1-42}$ exposure, caused the activation of calpain that in turn elicited a cleavage of the $\mathrm{Na}^{+} / \mathrm{Ca}^{2+}$ exchanger isoform NCX3. This cleavage generated a hyperfunctional form of the antiporter and increased NCX currents $\left(\mathrm{I}_{\mathrm{NCX}}\right)$ in the reverse mode of operation. Interestingly, this NCX3 calpain-dependent cleavage was essential for the A $\beta_{1-42}$-dependent $\mathrm{I}_{\mathrm{NCX}}$ increase. Indeed, the calpain inhibitor calpeptin and the removal of the calpain-cleavage recognition sequence, via site-directed mutagenesis, abolished this effect. Moreover, the enhanced NCX3 activity was paralleled by an increased Ca ${ }^{2+}$ content in the endoplasmic reticulum (ER) stores. Remarkably, the silencing in PC-12 cells or the knocking-out in mice of the ncx 3 gene prevented the enhancement of both $\mathrm{I}_{\mathrm{NCX}}$ and $\mathrm{Ca}^{2+}$ content in ER stores, suggesting that NCX3 was involved in the increase of ER Ca ${ }^{2+}$ content stimulated by A $\beta_{1-42}$. By contrast, in the late phase $(72 \mathrm{~h})$, when the NCX3 proteolytic cleavage abruptly ceased, the occurrence of a parallel reduction in ER $\mathrm{Ca}^{2+}$ content triggered ER stress, as revealed by caspase-12 activation. Concomitantly, the late increase in $\left[\mathrm{Ca}^{2+}\right]_{\mathrm{i}}$ coincided with neuronal death. Interestingly, NCX3 silencing caused an earlier activation of A $\beta_{1-42}$-induced caspase-12. Indeed, in NCX3-silenced neurons, $\mathrm{A} \beta_{1-42}$ exposure hastened caspase-dependent apoptosis, thus reinforcing neuronal cell death. These results suggest that $\mathrm{A} \beta_{1-42}$, through $\mathrm{Ca}^{2+}$-dependent calpain activation, generates a hyperfunctional form of $\mathrm{NCX} 3$ that, by increasing $\mathrm{Ca}^{2+}$ content into $\mathrm{ER}$, delays caspase-12 activation and thus neuronal death.

\section{Introduction}

Alzheimer's disease (AD), the most common form of dementia, is characterized by abnormal amyloid- $\beta$ protein $(A \beta)$ metabolism. $\mathrm{A} \beta$ accumulation in the brain and synaptic synapse loss are $\mathrm{AD}$ pathological hallmarks. A large bulk of studies has shown that $\mathrm{A} \beta$ neurotoxicity is closely related to an alteration of intracellular calcium concentration $\left(\left[\mathrm{Ca}^{2+}\right]_{\mathrm{i}}\right)$ homeostasis. These changes in $\left[\mathrm{Ca}^{2+}\right]_{\mathrm{i}}$ homeostasis, as a result of $\mathrm{A} \beta$ cytotoxicity, may induce an exaggerated endoplasmic reticulum (ER) $\mathrm{Ca}^{2+}$ release with the consequent unfolded protein accumulation and the activa-

Received Dec. 23, 2011; revised May 10, 2012; accepted May 12, 2012.

Author contributions: A.P., A. Secondo, P.M., and L.A. designed research; A.P., A. Secondo, C.D., M.C., A.E., F.B., A. Scorziello, and R.S. performed research; A.P. and C.D. analyzed data; A.P., A. Secondo, P.M., G.D., and L.A. wrote the paper.

This work was supported by Grant COFIN 2008, Ricerca-Sanitaria (Grant RF-FSL352059), Ricerca finalizzata (2006), Ricerca-Oncologica (2006), Progetto-Strategico (2007), Progetto Ordinario (2007), Ricerca finalizzata (2009), and Ricerca-Sanitaria progetto Ordinario (2008) by Ministero della Salute (all L.A.). We thank Dr. Paola Merolla for the editorial revision and Pellegrino Lippiello, Vincenzo Grillo, and Carmine Capitale for their technical assistance.

*A.P., A. Secondo, and P.M. contributed equally to this work.

Correspondence should be addressed to Lucio Annunziato, Division of Pharmacology, Department of Neuroscience, School of Medicine, “Federico II" University of Naples, Via Pansini 5, 80131 Naples, Italy. E-mail: lannunzi@unina.it.

DOI:10.1523/JNEUROSCI.6429-11.2012

Copyright $\odot 2012$ the authors $\quad 0270-6474 / 12 / 3210609-09 \$ 15.00 / 0$ tion of the ER stress-induced apoptosis pathway (Paschen, 2003; Chakroborty et al., 2009). These transductional events may occur through calpain-mediated caspase- 12 activation, a specific ER stress marker, and can also lead to caspase-3 activation (Morishima et al., 2002). Interestingly, ER stress and sustained changes in $\left[\mathrm{Ca}^{2+}\right]_{\mathrm{i}}$ signaling occur before cognitive decline in AD (Bezprozvanny and Mattson, 2008).

The $\mathrm{Na}^{+} / \mathrm{Ca}^{2+}$ exchanger (NCX), a family of neuronal plasma-membrane proteins composed of three different isoforms, NCX1, NCX2, and NCX3 (Nicoll et al., 1990; Li et al., 1994; Nicoll et al., 1996; Annunziato et al., 2004), couples, in a bidirectional manner, the exchange of $3 \mathrm{Na}^{+}$for $1 \mathrm{Ca}^{2+}$, thereby playing a relevant role in maintaining intracellular free $\mathrm{Ca}^{2+}$ homeostasis (Blaustein and Lederer, 1999). In particular, it has recently been demonstrated that the NCX1 isoform displays a functional relationship with $\mathrm{Ca}^{2+}$ refilling into ER (Sirabella et al., 2009). More specifically, NCX1 upregulation elicited by oxygen and glucose deprivation (OGD) is involved in $\mathrm{Ca}^{2+}$ refilling into $\mathrm{ER}$, thus exerting a neuroprotective role (Sirabella et al., 2009).

Furthermore, the NCX3 isoform, which is selectively expressed in the brain and skeletal muscle (Papa et al., 2003), plays a fundamental role in buffering intracellular $\mathrm{Ca}^{2+}$ and $\mathrm{Na}^{+}$overload occurring under physiological and pathophysiological con- 
ditions (Condrescu et al., 1995; Linck et al., 1998; Secondo et al., 2007). Indeed, neurons silenced with siRNA-NCX3 or derived from $n c \times 3-/-$ mice display a remarkable vulnerability in both in vivo and in vitro hypoxic conditions (Pignataro et al., 2004; Molinaro et al., 2008). These findings suggest that NCX-induced buffering of $\mathrm{Ca}^{2+}$ overload during exposure of neurons to hypoxic conditions may exert a neuroprotective function by facilitating ER $\mathrm{Ca}^{2+}$ refilling.

Interestingly, it has been reported that during brain ischemia and excitotoxicity, $\mathrm{NCX} 3$ may be cleaved by the $\mathrm{Ca}^{2+}$-activated protease calpain in the $\mathrm{Ca}^{2+}$ regulatory domain (Bano et al., 2005), thus suggesting a close relationship between calpain and NCX activity. In AD, both calpain activation (Vosler et al., 2008) and changes in NCX expression and activity have been described. Indeed, in the synaptic terminals obtained from the brain cortex of AD patients, NCX activity is increased (Colvin et al., 1994), NCX2 protein expression is upregulated (Sokolow et al., 2011), NCX3 native $105 \mathrm{kDa}$ band is downregulated (Sokolow et al., 2011), and NCX1, NCX2, and NCX3 colocalize with $\mathrm{A} \beta$ in synaptic terminals (Sokolow et al., 2011).

Owing to this evidence, by means of patch-clamp, Fura-2 acetoxymethyl-ester (Fura-2AM) microfluorometry, Western blot, chimera strategies, site-directed mutagenesis, and deletion mutagenesis, we characterized the effects of $\mathrm{A} \beta_{1-42}$ on NCX expression and activity, the molecular mechanisms underlying the $\mathrm{A} \beta_{1-42}$-mediated effects on the NCX isoforms, the molecular determinants responsible for the effects of $\mathrm{A} \beta_{1-42}$ on NCX, and the role of NCX isoforms in $\mathrm{Ca}^{2+}$ refilling into ER, caspase-12 activation, and neuronal death.

\section{Materials and Methods}

NCX3 knock-out mice. All experiments on ncx3-/- mice, already described (Molinaro et al., 2008, 2011), were performed according to the international guidelines for animal research and approved by the Animal Care Committee of "Federico II" University of Naples, Italy.

Materials. $\mathrm{A} \beta_{1-42}$, as well as all other unmentioned materials, was from Sigma-Aldrich. Nerve growth factor (NGF) and tetrodotoxin (TTX) were from Alomone Labs. Protease inhibitor mixture II was purchased from Calbiochem. RPMI1640, horse serum, fetal bovine serum, Dulbecco's modified Eagle's medium, nutrient mixture F-12, L-glutamine, fetal calf serum, Earle's balanced salt solution, and phosphate-buffed saline (PBS) were from Gibco-BRL. Fura-2AM and SBFI-AM were from Invitrogen.

Cell cultures. Baby hamster kidney (BHK) cells stably transfected with canine cardiac NCX1 or rat brain NCX3 were grown on plastic dishes in a mix of DMEM and Ham's F12 medium (1:1) supplemented with 5\% fetal bovine serum, $100 \mathrm{U} / \mathrm{ml}$ penicillin, and $100 \mu \mathrm{g} / \mathrm{ml}$ streptomycin (Linck et al., 1998). Rat pheochromocytoma (PC-12) cells were grown and differentiated as previously described (Greene and Tischler, 1976; Pannaccione et al., 2005). Hippocampal neurons were obtained from the brains of embryonic day $18 n c x 3+/+$ and $n c x 3-/-$ mouse embryos of either sex, as previously described (Scorziello et al., 2001). Neurons were used after 8 DIV.

$A \beta$ treatments. Synthetic $\mathrm{A} \beta_{1-42}$ was dissolved in PBS to obtain a $1 \mathrm{~mm}$ stock solution, incubated for $48 \mathrm{~h}$ at $37^{\circ} \mathrm{C}$ to pre-aggregate the peptide and was stored at $-20^{\circ} \mathrm{C}$ (Lorenzo and Yankner, 1994). A $\beta_{1-42}$ was added to the culture medium at the final concentration of $5 \mu \mathrm{M}$, and the cells were incubated in the presence of the pre-aggregated peptide for $24 \mathrm{~h}$. In dose-response experiments, $A \beta_{1-42}$ was added at final concentrations ranging from 0.01 to $10 \mu \mathrm{M}$. Before all experiments, we tested a pre-aggregated preparation of the $A \beta_{1-42}$. SDS-PAGE was performed using monoclonal antibody $6 \mathrm{E} 10$, which recognizes an epitope within residues 1-17 of human $A \beta$ (Millipore Bioscience Research Reagents). Results showed that the oligomers between 18 and $32 \mathrm{kDa}$ were the major species of $\mathrm{A} \beta_{1-42}$ peptide in the preparation (data not shown).

$R N A$ silencing. The mammalian expression vector $\mathrm{pSUPER}$.retro.puro (OligoEngine) was used to express siRNA against NCX1 and NCX3 and
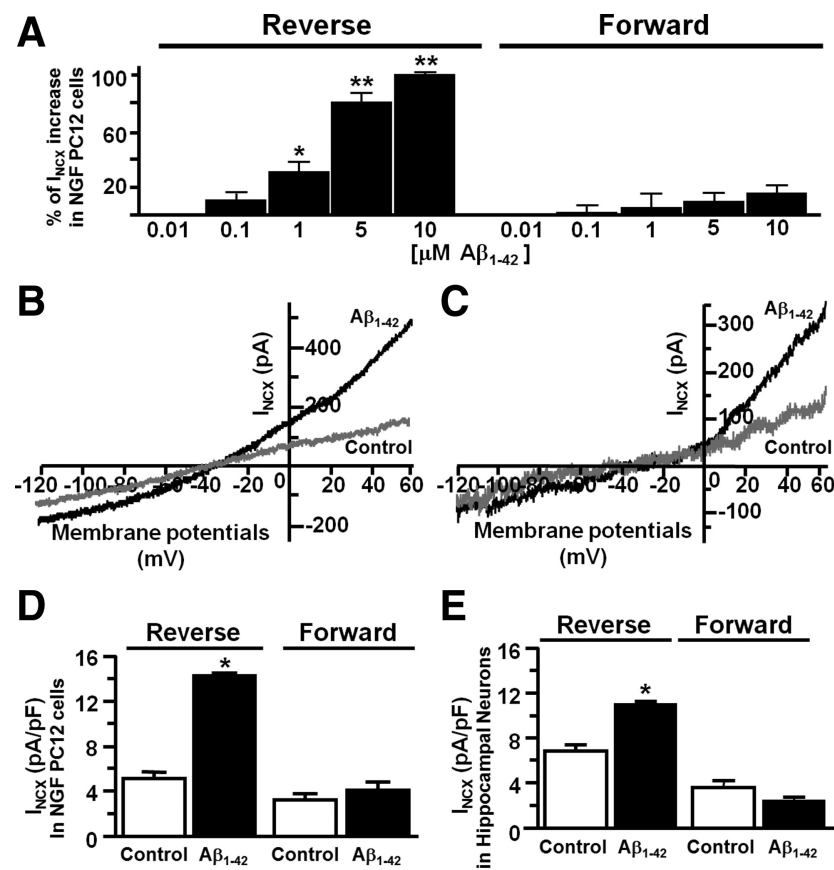

$E$

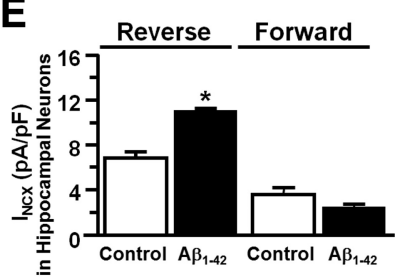

$\mathbf{F}$

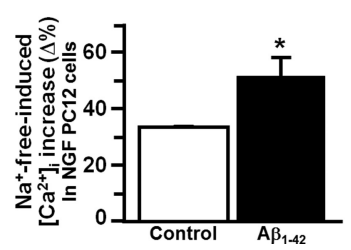

G

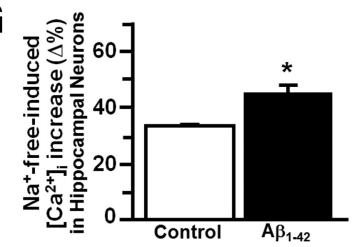

Figure 1. Effect of $A \beta_{1-42}$ on NCX activity in hippocampal neurons and NGF-differentiated $\mathrm{PC}-12$ cells. $A$, Quantification of $\mathrm{A} \beta_{1-42}$ concentration-dependent $(0.01-10 \mu \mathrm{M})$ effect on $\mathrm{I}_{\mathrm{NCX}}$ in the reverse and forward modes of operation. Values are expressed as percentage mean \pm SEM of 3 independent experimental sessions ( $n=12$ for each group). $\boldsymbol{B}, \boldsymbol{C}$, Representative $I_{N C X}$ superimposed traces recorded under control conditions (gray trace) and after $24 \mathrm{~h}$ of $5 \mu \mathrm{m}$ $A \beta_{1-42}$ (black trace) in NGF-differentiated PC12 cells $(\boldsymbol{B})$ and in primary hippocampal neurons (C). $\boldsymbol{D}, \boldsymbol{E}$, Quantification of $\mathrm{I}_{\mathrm{NCX}}$ represented in $\boldsymbol{B}$ and $\boldsymbol{C}$, respectively. Values are expressed as mean \pm SEM of current densities of 3 independent experimental sessions ( $n=16$ for each group). $F, G$, Quantification of $N C X$ activity in the reverse mode of operation elicited by $\mathrm{Na}^{+}$ free perfusion under control conditions and after exposure to $A \beta_{1-42}(5 \mu \mathrm{m}, 24 \mathrm{~h})$ recorded in NGFdifferentiated PC12 cells $(\boldsymbol{F})$ and hippocampal neurons $(\boldsymbol{G})$. Values are expressed as percentage mean \pm SEM of 3 independent experimental sessions ( $n=60$ for each group). ${ }^{*} p<0.05$ versus control group; ${ }^{* *} p<0.05$ versus control and the previous lower concentration of $A \beta_{1-42}$.

their mismatch sequences in PC-12 cells. These vectors were prepared as previously reported (Secondo et al., 2007). After $15 \mathrm{~h}$ plating, PC-12 cells were transfected with pSUPER-NCX1, pSUPER-NCX3, pSUPER-mismatch sequences by Lipofectamine 2000 (Invitrogen) standard protocol.

Generation and stable expression of wild-type, mutant, and chimeric NCX. Dog heart NCX1.1 and rat brain NCX3.3 cDNAs, generous gifts of Dr. Kenneth D. Philipson (David Geffen School of Medicine, University of California, Los Angeles, Los Angeles, CA), were cloned into pcDNA3.1 expression vector, whereas NCX3/NCX1 chimeras were a generous gift from Dr. Takahiro Iwamoto (Fukuoka University, Fukuoka, Japan). NCX3 mutants were generated with QuikChange site-directed mutagenesis kit (Stratagene) by removing the amino acid region 292-708 from $\mathrm{NCX}_{\mathrm{WT}}(\mathrm{NCX} 3 \Delta \mathrm{f})$ or by replacing the amino acids lysin ${ }^{370}$ and lysin ${ }^{371}$ with tryptophan ${ }^{370}$ and tryptophan ${ }^{371}\left(\mathrm{NCX}_{\mathrm{KK} 370 \mathrm{ww}}\right)$. All mutants were verified by whole sequencing on both DNA strands (Primm).

All cDNAs were transfected in the BHK cell line by Lipofectamine 2000 following the manufacturer's instructions. Stable cell lines were selected by G418 resistance and by a Ca ${ }^{2+}$-killing procedure (Iwamoto et al., 1998).

Electrophysiology. NCX currents $\left(\mathrm{I}_{\mathrm{NCX}}\right)$ in hippocampal mouse neurons, NGF-differentiated PC-12, and BHK cells were recorded by the patch-clamp technique in whole-cell configuration using the commer- 
A

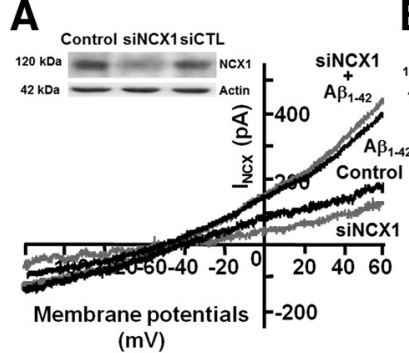

$(\mathrm{mV})$

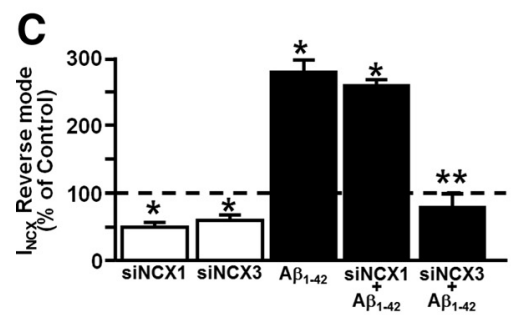

E

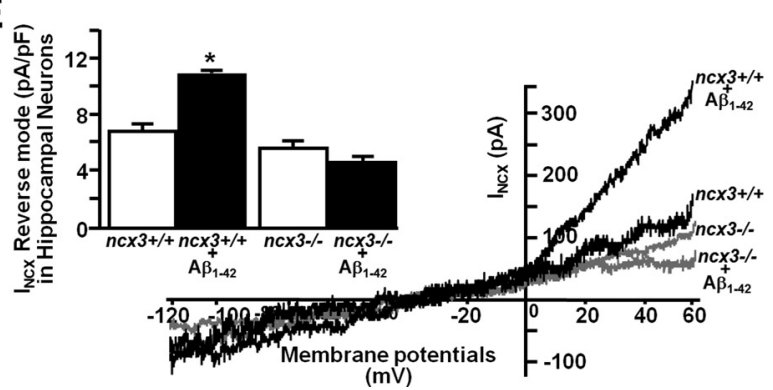

Figure 2. Effect of $N C X 3$ silencing or knocking-out on $A \beta_{1-42}$-induced upregulation of $I_{N C X}$ in NGF-differentiated PC-12 cells and hippocampal neurons. $A$, Representative Western blot of $N C X 1$ silencing (top) and superimposed representative traces of $I_{N C X}$ recorded from control, control plus siNCX1, after $5 \mu \mathrm{MA} \beta_{1-42}$ for $24 \mathrm{~h}$ and after $5 \mu \mathrm{MA} \beta_{1-42}$ for $24 \mathrm{~h}$ plus siNCX1 in NGF-differentiated $P C 12$ cells. $\boldsymbol{B}$, Representative Western blot of siNCX3 on protein expression (top) and superimposed representative traces of $\mathrm{I}_{N C X}$ recorded from control, control plus siNCX3, after $5 \mu \mathrm{M} \mathrm{A} \beta_{1-42}$ for $24 \mathrm{~h}$, and after $5 \mu \mathrm{M} \mathrm{A} \beta_{1-42}$ for $24 \mathrm{~h}$ plus siNCX3 in NGF-differentiated PC12 cells. C, Quantification of $I_{N C X}$ represented in $\boldsymbol{A}$ and $\boldsymbol{B}$. Values are expressed as percentage mean \pm SEM of 3 independent experimental sessions ( $n=15$ for each group). $\boldsymbol{D}$, Representative Western blot of NCX1 and NCX2 protein expression in NGF-differentiated PC12 cells under control conditions and after $24 \mathrm{~h}$ of $5 \mu \mathrm{mA} \beta_{1-42}$ in the presence and in absence of siNCX3. $E$, Representative $I_{N C X}$ superimposed traces recorded from $n c x 3+/+$ and $n \subset x 3-/-$ primary hippocampal neurons under control conditions and after $24 \mathrm{~h}$ of $5 \mu \mathrm{MA} \beta_{1-42}$ exposure. Inset depicts the quantification of $\mathrm{I}_{\mathrm{NC}}$ under the conditions previously reported. Values are expressed as mean \pm SEM of 3 independent experimental sessions ( $n=16$ for each group). ${ }^{*} p<0.05$ versus control group; ${ }^{* *} p<0.05$ versus $A \beta_{1-42}$.

cially available amplifier Axopatch200B and Digidata1322A interface (Molecular Devices), as previously described by Secondo (2009) and Molinaro (2008). $\mathrm{I}_{\mathrm{NCX}}$ were recorded starting from a holding potential of $-60 \mathrm{mV}$ up to a short-step depolarization at $+60 \mathrm{mV}(60 \mathrm{~ms})$. A descending voltage ramp from $+60 \mathrm{mV}$ to $-120 \mathrm{mV}$ was applied. $\mathrm{I}_{\mathrm{NCX}}$ recorded in the descending portion of the ramp (from $+60 \mathrm{mV}$ to -120 $\mathrm{mV}$ ) were used to plot the current-voltage $(I-V)$ relation curve. The $\mathrm{I}_{\mathrm{NCX}}$ magnitude was measured at the end of $+60 \mathrm{mV}$ (reverse mode) and at the end of $-120 \mathrm{mV}$ (forward mode), respectively. The $\mathrm{Ni}^{2+}$ insensitive component was subtracted from total currents to isolate $\mathrm{I}_{\mathrm{NCX}}$. The neurons were perfused with external Ringer's solution containing the following (in mM): $126 \mathrm{NaCl}, 1.2 \mathrm{NaHPO}_{4}, 2.4 \mathrm{KCl}, 2.4 \mathrm{CaCl}_{2}, 1.2$ $\mathrm{MgCl}_{2}, 10$ glucose, and $18 \mathrm{NaHCO}_{3}, \mathrm{pH}$ 7.4. Twenty millimolar tetraethylammonium (TEA), $50 \mathrm{~nm}$ TTX, and $10 \mu \mathrm{m}$ nimodipine were added to Ringer's solution to abolish potassium, sodium, and calcium currents. The dialyzing pipette solution contained the following (in $\mathrm{mM}$ ): 100 K-gluconate, 10 TEA, $20 \mathrm{NaCl}, 1 \mathrm{Mg}$-ATP, $0.1 \mathrm{CaCl}_{2}, 2 \mathrm{MgCl}_{2}, 0.75$ EGTA, and $10 \mathrm{HEPES}$, adjusted to $\mathrm{pH} 7.2$ with $\mathrm{Cs}(\mathrm{OH})_{2}$. Possible changes in cell size occurring after specific treatments were calculated by monitoring the capac-
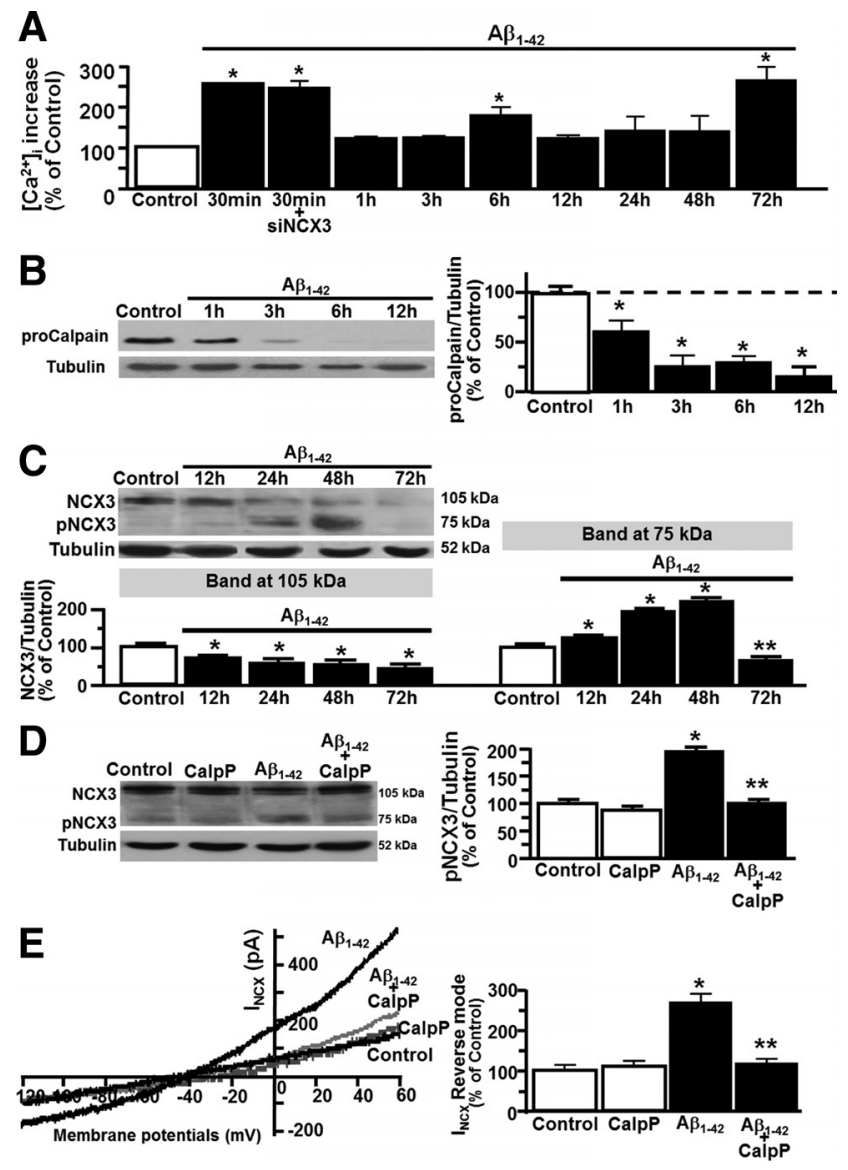

Figure 3. Effect of $A \beta_{1-42}$ on calpain activation and on the formation of NCX3 proteolytic fragment in NGF-differentiated PC-12 cells. A, Quantification of the time-dependent effect of $A \beta_{1-42}$ on $\left[\mathrm{Ca}^{2+}\right]_{\mathrm{i}}$. Values are expressed as percentage mean $\pm \mathrm{SEM}$ of 3 independent experimental sessions ( $n=60$ for each group). $\boldsymbol{B}$, Representative Western blot and densitometric quantification of calpain activation under control conditions, after $1,3,6$, and $12 \mathrm{~h}$ of $5 \mu \mathrm{m}$ $A \beta_{1-42}$ exposure. Values are expressed as percentage mean \pm SEM of 3 independent experimental sections. $C$, Representative Western blot and densitometric quantification of NCX3 protein expression and its proteolytic fragment under control conditions, after $12,24,48$, and $72 \mathrm{~h}$ of $5 \mu \mathrm{MA} \beta_{1-42}$. Values are expressed as percentage mean \pm SEM of 3 independent experimental sections. ${ }^{*} p<0.05$ versus control group; ${ }^{* *} p<0.05$ versus $A \beta_{1-42} 12,24$, and $48 \mathrm{~h}$ $(\boldsymbol{A}-\boldsymbol{C})$. D, Representative Western blot and densitometric quantification of the proteolytic fragment of NCX3 in the presence and in the absence of calpeptin (CalpP, $100 \mathrm{~nm}$ ) under control conditions and after $24 \mathrm{~h}$ of $A \beta_{1-42}$ exposure. Values are expressed as percentage mean $\pm \mathrm{SEM}$ of 3 independent experimental sections. $\boldsymbol{E}$, Representative superimposed traces of $\mathrm{I}_{\mathrm{NCX}}$ and quantification in the presence and in absence of CalpP under control conditions and after $24 \mathrm{~h}$ of $A \beta_{1-42}$. Values are expressed as percentage mean \pm SEM of 3 independent experimental sessions ( $n=20$ for each group). ${ }^{*} p<0.05$ versus control; ${ }^{* *} p<0.05$ versus $A \beta_{1-42}(\boldsymbol{D}, \boldsymbol{E})$.

itance of each cell membrane, which is directly related to the membrane surface area, and by expressing the current amplitude data as current densities $(\mathrm{pA} / \mathrm{pF})$. Capacitive currents were estimated from the decay of the capacitive transient induced by $5 \mathrm{mV}$ depolarizing pulses from a holding potential of $-80 \mathrm{mV}$ and acquired at a sampling rate of $50 \mathrm{kHz}$. The capacitance of the membrane was calculated according to the following equation: $C_{\mathrm{m}}=\tau_{\mathrm{c}} \cdot I_{\mathrm{o}} / \Delta E_{\mathrm{m}}\left(1-I_{\circ} / I_{\mathrm{o}}\right)$, where $C_{\mathrm{m}}$ is membrane capacitance, $\tau_{\mathrm{c}}$ is the time constant of the membrane capacitance, $I_{\mathrm{o}}$ is the maximum capacitance current value, $\Delta E_{\mathrm{m}}$ is the amplitude of the voltage step, and $I_{\infty}$ is the amplitude of the steady state current.

$\left[\mathrm{Ca}^{2+}\right]_{i}$ and $\left[\mathrm{Na}^{+}\right]$i measurement. $\left[\mathrm{Ca}^{2+}\right]_{\mathrm{i}}$ was measured by single-cell computer-assisted video-imaging in hippocampal mouse neurons, NGFdifferentiated PC-12, and BHK cells loaded with $10 \mu \mathrm{m}$ Fura-2AM (Calbiochem) for $30 \mathrm{~min}$ at $37^{\circ} \mathrm{C}$ (Grynkiewicz et al., 1985; Secondo et al., 2007).

At the end of the Fura-2AM loading period, the coverslips were placed in a perfusion chamber (Medical System) mounted onto an Axiovert200 
A
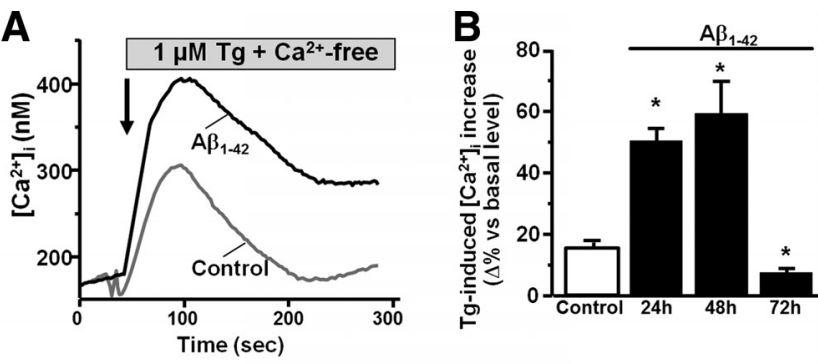

C

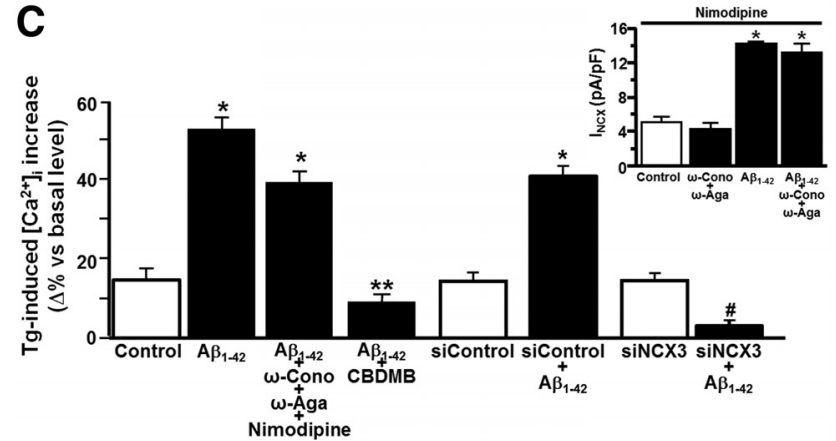

D

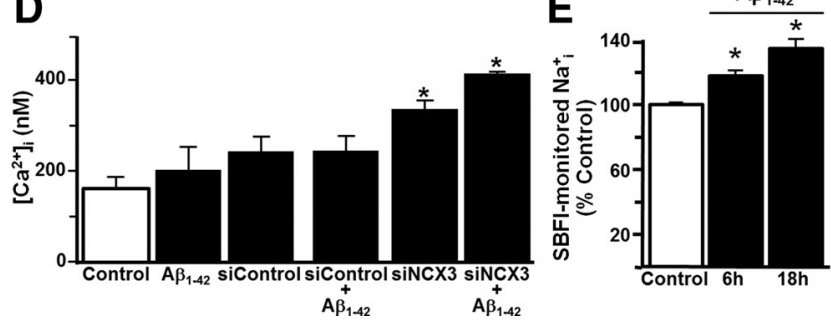

Figure 4. Effect of $\mathrm{NCX} 3$ silencing on $\mathrm{Ca}^{2+}$ content in ER and $\left[\mathrm{Ca}^{2+}\right]_{\mathrm{i}}$ in NGF-differentiated $P C-12$ cells exposed to $A \beta_{1-42}$. $A$, Representative superimposed single-cell traces of the effect of $1 \mu \mathrm{m} \mathrm{Tg}$ on $\left[\mathrm{Ca}^{2+}\right]_{\mathrm{i}}$ in $\mathrm{Ca}^{2+}$-free $\left(0 \mathrm{Ca}^{2+} ; 1.5 \mathrm{~mm}\right.$ EGTA) under control conditions (gray trace) and after $24 \mathrm{~h} \mathrm{~A} \beta_{1-42}$ (black trace). $B$, Quantification of $A \beta_{1-42}$ effect on Tg-induced $\left[\mathrm{Ca}^{2+}\right]_{\mathrm{i}}$ release. Values are expressed as mean \pm SEM of 3 independent experimental sessions ( $n=50$ for each group). C, Quantification of the effects of CB-DMB, several $\mathrm{Ca}^{2+}$ channel blockers, siControl, and siNCX3 after $24 \mathrm{~h}$ of $5 \mu \mathrm{mA} \beta_{1-42}$ on Tg-induced $\left[\mathrm{Ca}^{2+}\right]_{\mathrm{i}}$ release $(n=$ 50 for each group). C, Inset, Quantification of the effects of $\mathrm{Ca}^{2+}$ channel blockers on NCX currents under control conditions and after $24 \mathrm{~h} 5 \mu \mathrm{MA} \beta_{1-42}$ ( $n=16$ for each group). Values are expressed as mean \pm SEM of 3 independent experimental sessions. $D$, Quantification of the effect of $A \beta_{1-42}$ on $\left[\mathrm{Ca}^{2+}\right]_{i}$ in the presence and in the absence of sinCX3. Values are expressed as percentage mean \pm SEM of 3 independent experimental sessions $(n=60$ for each experimental group). $\boldsymbol{E}$, Quantification of the time-dependent effect of $A \beta_{1-42}$ on $\left[\mathrm{Na}^{+}\right]_{\mathrm{i}}$. Values are expressed as percentage mean \pm SEM of 3 independent experimental sessions ( $n=50$ for each experimental group). ${ }^{*} p<0.05$ versus their untreated controls; ${ }^{* *} p<0.05$ versus $A \beta_{1-42}$ group; $\# p<0.05$ versus all groups.

microscope (Carl Zeiss) equipped with a FLUAR $40 \times$ oil objective lens. The experiments were carried out with a digital imaging system composed of a MicroMax 512BFT cooled CCD camera (Princeton Instruments), LAMBDA10-2 filter wheeler (Sutter Instruments), and Meta-Morph/ MetaFluor Imaging System software (Universal Imaging). After loading, cells were alternatively illuminated at wavelengths of 340 and $380 \mathrm{~nm}$ by a Xenon lamp. The emitted light was passed through a $512 \mathrm{~nm}$ barrier filter. Fura-2AM fluorescence intensity was measured every 3 s. Ratiometric values were automatically converted by the software to $\left[\mathrm{Ca}^{2+}\right]_{\mathrm{i}}$ using a preloaded calibration curve obtained in preliminary experiments (Grynkiewicz et al., 1985). NCX activity was evaluated as $\mathrm{Ca}^{2+}$ uptake through the reverse mode by switching the normal Krebs medium to $\mathrm{Na}^{+}$-deficient $\mathrm{N}$-methyl glucamine $\left(\mathrm{NMDG}^{+}\right)$medium $\left(\mathrm{Na}^{+}\right.$-free $)$as follows (in mM): $5.5 \mathrm{KCl}, 147 \mathrm{NMDG}, 1.2 \mathrm{MgCl}_{2}, 1.5 \mathrm{CaCl}_{2}, 10$ glucose, and 10 HEPES, pH 7.4. The irreversible and selective inhibitor of the sarco(endo)plasmic reticulum $\mathrm{Ca}^{2+}$ ATPase (SERCA) thapsigargin (Tg; $1 \mu \mathrm{M}$ ) was added to the medium $10 \mathrm{~min}$ before the beginning of the
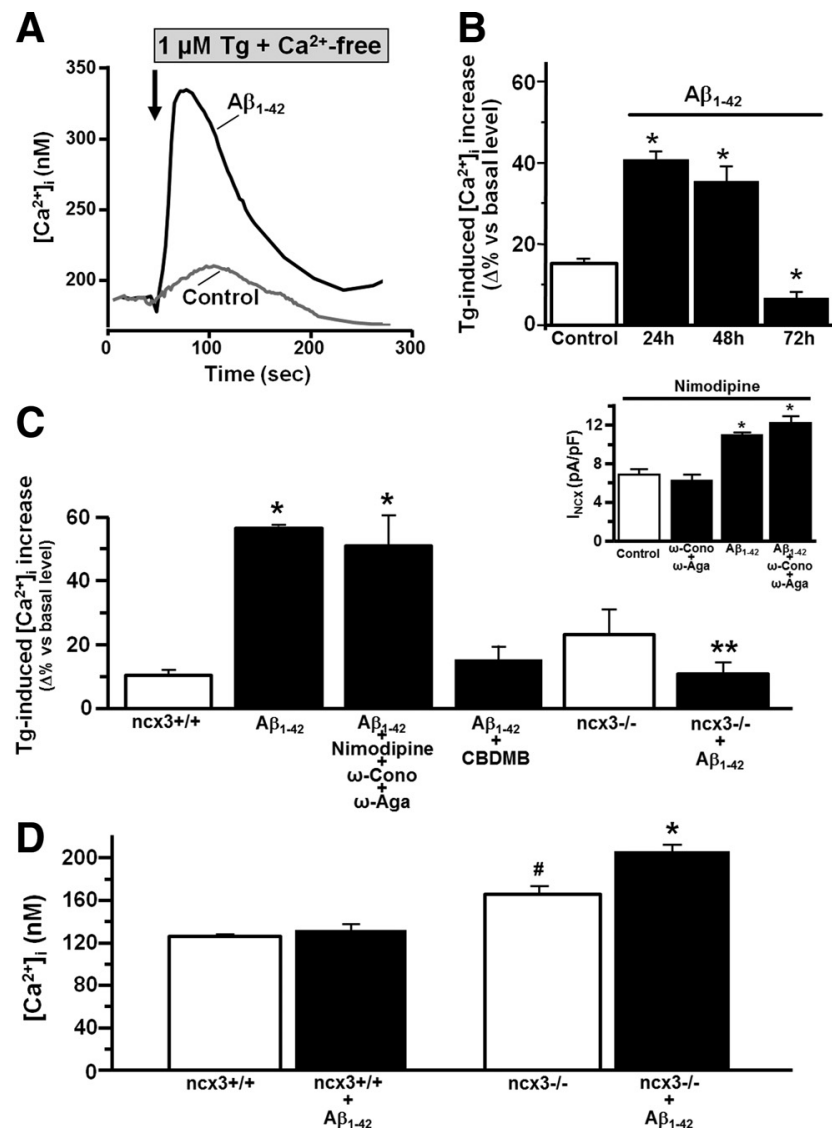

Figure 5. Effect of $\mathrm{NCX} 3$ knocking-out on $\mathrm{Ca}^{2+}$ content in $\mathrm{ER}$ and $\left[\mathrm{Ca}^{2+}\right]_{\mathrm{i}}$ in primary hippocampal neurons from $n c x 3+/+$ and $n c x 3-/-$ mice exposed to $A \beta_{1-42} . A$, Representative superimposed single-cell traces of the effect of $1 \mu \mathrm{M}$ Tg on $\left[\mathrm{Ca}^{2+}\right]_{\mathrm{i}}$ in $\mathrm{Ca}^{2+}$-free $\left(0 \mathrm{Ca}^{2+} ; 1.5\right.$ mM EGTA) under control conditions (gray trace) and after $24 \mathrm{~h} \mathrm{~A} \beta_{1-42}$ (black trace). $\boldsymbol{B}$, Quantification of $A \beta_{1-42}$ effect on Tg-induced $\left[\mathrm{Ca}^{2+}\right]_{\mathrm{i}}$ release. Values are expressed as mean $\pm \mathrm{SEM}$ of 3 independent experimental sessions ( $n=50$ for each group). $C$, Quantification of the effects of CB-DMB, several $\mathrm{Ca}^{2+}$ channel blockers and NCX3 knock-out on Tg-induced $\left[\mathrm{Ca}^{2+}\right]_{\mathrm{i}}$ release measured after 24 h of $5 \mu \mathrm{MA} \beta_{1-42}$ ( $n=50$ for each experimental group). C, Inset, Quantification of the effects of $\mathrm{Ca}^{2+}$ channel blockers on NCX currents under control condition and after $24 \mathrm{~h} 5 \mu \mathrm{MA} \beta_{1-42}$. Values are expressed as mean \pm SEM of 3 independent experimental sessions ( $n=16$ for each experimental group). $\boldsymbol{D}$, Quantification of the effect of $A \beta_{1-42}$ on $\left[\mathrm{Ca}^{2+}\right]_{\mathrm{i}}$ in the presence and in the absence of NCX3 $(n c \times 3-/-)$. Values are expressed as percentage mean \pm SEM of 3 independent experimental sessions $(n=60$ for each experimental group). ${ }^{*} p<0.05$ versus their respective untreated controls; ${ }^{* *} p<0.05$ versus $A \beta_{1-42}$; $\#$ $p<0.05$ versus $n c x 3+/+$.

recordings, as previously described (Secondo et al., 2007). NCX activity was calculated as $\Delta \%$ of peak/basal $\left[\mathrm{Ca}^{2+}\right]_{\mathrm{i}}$ values after the perfusion with $\mathrm{Na}^{+}$-free medium. $\left[\mathrm{Na}^{+}\right] \mathrm{i}$ measurement was performed by SBFI-AM incubated at $10 \mathrm{mM}$ in the presence of pluronic acid $(0.02 \%)$ for $1 \mathrm{~h}$ at $37^{\circ} \mathrm{C}$.

Assessment of neuronal death. Cell death, detected by double staining with fluorescein diacetate (FDA) $(36 \mu \mathrm{mol} / \mathrm{L})$ and propidium iodide (PI) ( $7 \mu \mathrm{mol} / \mathrm{L})$, was measured by calculating the ratio between dead and living cells, as previously described (Secondo et al., 2007).

Nuclear morphology was evaluated by using the fluorescent DNAbinding dye Hoechst 33258 already described (Pannaccione et al., 2005).

Western blot analysis. Cells were washed in PBS and collected by gentle scraping in ice-cold RIPA buffer to detect proteins. Nitrocellulose membranes were incubated with rabbit-polyclonal antibody anti-NCX3 (1: 3000; kindly provided by K. Philipson), or mouse monoclonal antiNCX1 (1:500; Swant), or mouse monoclonal anti-tubulin (1:1000), or rabbit polyclonal antibodies anti-caspase-12 (1:1000) and goat polyclonal anti-calpain (1:500) (Santa Cruz Biotechnology). Calpain activation was assessed by immunoblot analysis using a primary antibody that 
A
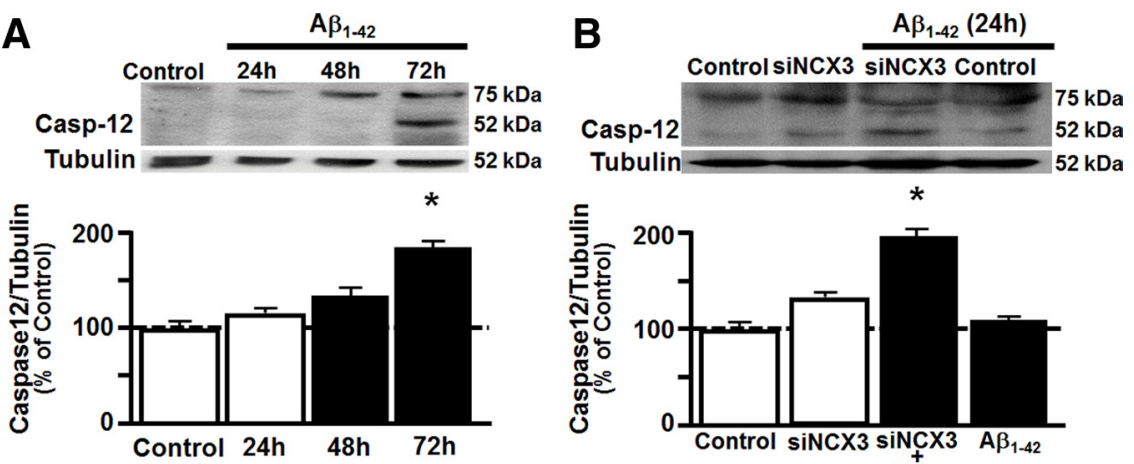

C
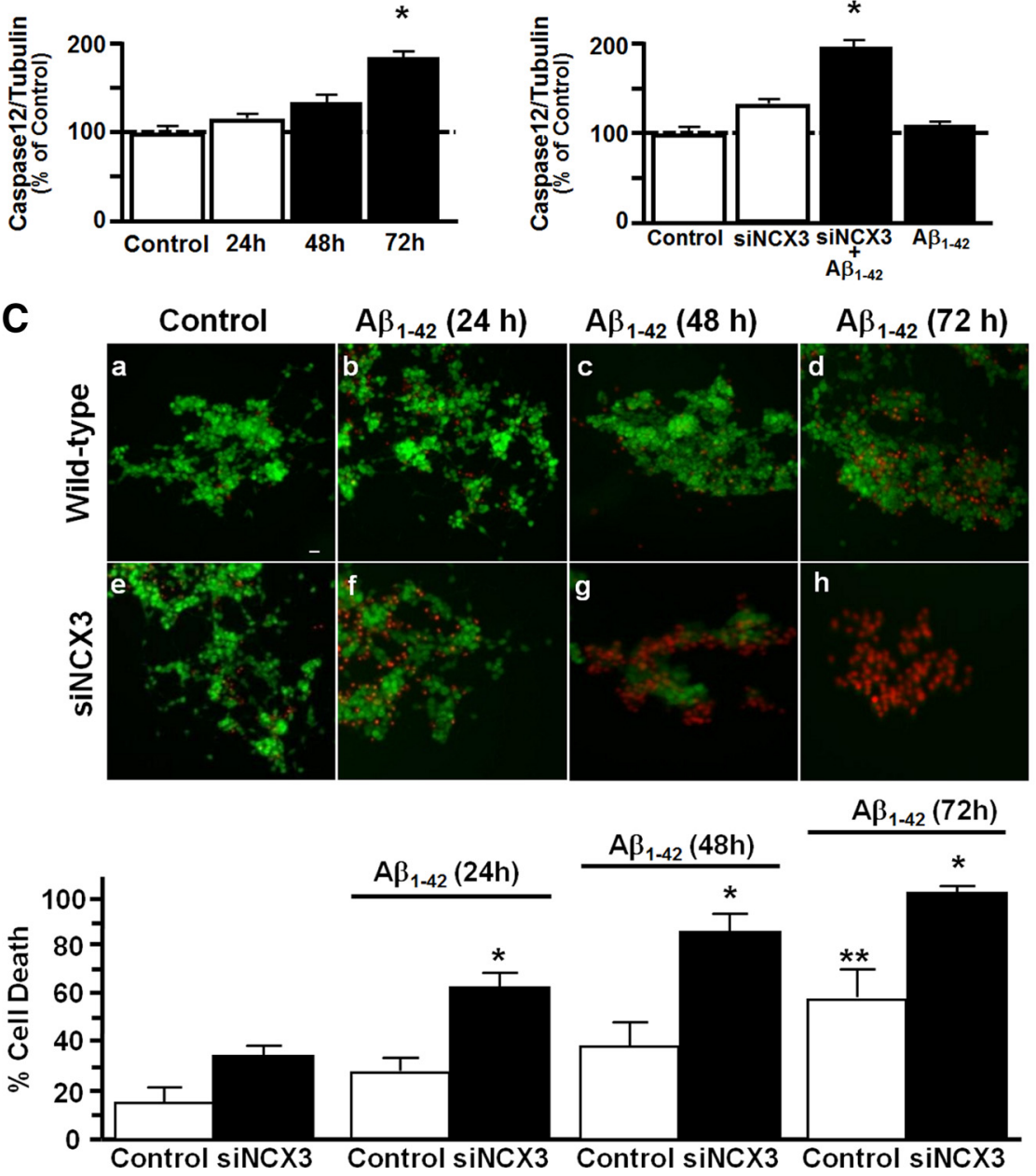

Figure 6. Effect of NCX3 silencing on caspase-12 activation and neuronal death, induced by $A \beta_{1-42}$ in NGF-differentiated PC-12 cells. $A$, Representative Western blot and densitometric quantification of the time-dependent effect of $5 \mu \mathrm{MA} \beta_{1-42}$ on caspase-12 activation. $\boldsymbol{B}$, Representative Western blot and densitometric quantification of caspase-12 activation under contro conditions and after $24 \mathrm{~h}$ of $A \beta_{1-42}$ in the presence or in the absence of siNCX3. Values are expressed as mean \pm SEM of 3 independent experimental sessions $(n=5)$. C Cell death measured in representative fluorescent images acquired under control conditions and after 24,48 , and $72 \mathrm{~h}$ of $A \beta_{1-42}$ in the presence $(\boldsymbol{e}-\boldsymbol{h})$ or in the absence of siNCX3 $(\boldsymbol{a}-\boldsymbol{d})$ and reported as a percentage of the ratio of the number of PI-positive cells/PI + FDA-stained-positive cells. Scale bar, $20 \mu \mathrm{m}$. ${ }^{*} p<0.05$ versus respective control group; ${ }^{* *} p<0.05$ versus untreated control.

recognizes the calpain large subunit domain, which is autolyzed in active calpain from the full length calpain at $130 \mathrm{kDa}$, as already reported (Goll et al., 2003; Scalia et al., 2011; Selimovic et al., 2011).

Statistical analysis. Statistical analyses were performed with ANOVA followed by Newman-Keuls test or Student's $t$ test. Differences were considered statistically significant at $p<0.05$.

\section{Results}

Effect of $A \boldsymbol{\beta}_{1-42}$ on NCX activity in hippocampal neurons and NGF-differentiated PC-12 cells

After $\mathrm{A} \beta_{1-42}$ exposure, $\mathrm{I}_{\mathrm{NCX}}$ were assessed in the reverse and forward modes of operation by patch-clamp in whole-cell configuration in both hippocampal and NGF-differentiated PC-12 cells. $\mathrm{A} \beta_{1-42}$ induced a significant concentration-dependent increase only in $\mathrm{I}_{\mathrm{NCX}}$ operating in the reverse mode, whereas it was ineffective on currents operating on the forward mode (Fig. $1 \mathrm{~A}-$ $E)$. Consistently, as revealed by Fura-2AM microfluorometry,
$\mathrm{Na}^{+}$-dependent NCX activity was significantly increased in the reverse mode of operation in hippocampal neurons and in NGF-differentiated PC-12 cells treated with $5 \mu \mathrm{M} \mathrm{A} \beta_{1-42}$ for $24 \mathrm{~h}$ (Fig. $1 F, G$ ).

\section{Effect of NCX3 silencing or knocking- out on $A \beta_{1-42}$-induced upregulation of $\mathrm{I}_{\mathrm{NCX}}$}

Patch-clamp experiments revealed that the silencing of NCX3, but not of NCX1, prevented the $\mathrm{A} \beta_{1-42}$-induced upregulation of $\mathrm{I}_{\mathrm{NCX}}$ in the reverse mode of operation in NGF-differentiated PC-12 cells (Fig. 2A$C)$. Under these experimental conditions, no compensatory upregulation of NCX1 and NCX2 occurred (Fig. 2D). Interestingly, $\mathrm{A} \beta_{1-42}$ treatment failed to increase $\mathrm{I}_{\mathrm{NCX}}$ in hippocampal neurons obtained from $n c \times 3-/-$ mice (Fig. $2 E$ ).

\section{Effect of $A \boldsymbol{\beta}_{1-42}$ on calpain activation and on the generation of NCX3 proteolytic fragment}

In NGF-differentiated PC-12 cells, the exposure to $5 \mu \mathrm{M} \mathrm{A} \beta_{1-42}$ caused: (a) an early increase in $\left[\mathrm{Ca}^{2+}\right]_{\mathrm{i}}$ at $30 \mathrm{~min}$, that was unaffected by NCX3 silencing (Fig. $3 A$ ) and prevented by extracellular $\mathrm{Ca}^{2+}$ removal (Pannaccione et al., 2005), (b) a second peak at $6 \mathrm{~h}$, and (c) a late peak at $72 \mathrm{~h}$ that was coincident with the neuronal death (see Fig. $6)$. At the other time points examined, the $\left[\mathrm{Ca}^{2+}\right]_{\mathrm{i}}$ returned to basal levels (Fig. $3 A$ ). Interestingly, the $\mathrm{A} \beta_{1-42}$-induced early increase in $\left[\mathrm{Ca}^{2+}\right]_{\mathrm{i}}$ triggered the activation of calpain, which occurred at $1 \mathrm{~h}$ and lasted up to $12 \mathrm{~h}$ (Fig. $3 B$ ). Immunoblot analysis revealed that after calpain activation, the NCX3 native band, detected at $\sim 105 \mathrm{kDa}$, decreased at $12,24,48$, and $72 \mathrm{~h}$, whereas the proteolytic band, migrating at $\sim 75 \mathrm{kDa}$, increased progressively from 12 to $48 \mathrm{~h}$ (Fig. $3 C)$. Thereafter, at $72 \mathrm{~h}$, the proteolytic band abruptly dropped (Fig. 3C). Interestingly, the selective calpain inhibitor calpeptin $(100$ nM) (Lee et al., 2000) completely prevented both the $\mathrm{A} \beta_{1-42}$-induced generation of the $\sim 75 \mathrm{kDa}$ proteolytic fragment (Fig. $3 D$ ) and the increase in $\mathrm{I}_{\mathrm{NCX}}$ in the reverse mode of operation (Fig. 3E).

Effect of NCX3 silencing or knocking-out on $\mathrm{Ca}^{2+}$ refilling into $\mathrm{ER}$ induced by $\mathrm{A} \boldsymbol{\beta}_{1-42}$

After 24 or $48 \mathrm{~h}$ of $\mathrm{A} \beta_{1-42}$ exposure, the SERCA inhibitor $\mathrm{Tg}$ induced a $\mathrm{Ca}^{2+}$ release from ER stores higher than that obtained under control conditions, both in hippocampal neurons and in NGF-differentiated PC-12 cells (Figs. 4 and 5). This demonstrated that, under these conditions, a larger accumulation of $\mathrm{Ca}^{2+}$ occurs in the ER (Figs. $4 A, B$ and $5 A, B$ ). Subsequently, at $72 \mathrm{~h}$, the increase in ER $\mathrm{Ca}^{2+}$ switched in a depletion (Figs. $4 B$, $5 B)$. The larger $A \beta_{1-42}$-induced ER-Ca ${ }^{2+}$ accumulation occurring at 24 and $48 \mathrm{~h}$ was prevented either by CB-DMB (300 nM) exposure or by silencing or knocking out of NCX3 (Figs. $4 C, 5 C$ ). 
On the other hand, the blockade of L-, N-, and P/Q-type voltage dependent calcium channels (VDCCs) with their specific inhibitors nimodipine $(10 \mu \mathrm{M})$, $\varpi$-conotoxin $(200 \mathrm{nM})$, and $\varpi$-agatoxin (200 nM), respectively, did not prevent $\mathrm{ER} \mathrm{Ca}^{2+}$ refilling induced by $\mathrm{A} \beta_{1-42}$ exposure (Figs. $4 C, 5 C$ ). Interestingly, the patch-clamp measurements revealed that the same specific inhibitors did not modify NCX activity under control conditions or after $\mathrm{A} \beta_{1-42}$ exposure (Figs. $4 C, 5 C$ insets).

At the cytosolic level, the silencing or the knocking out of NCX3 itself caused an increase in basal $\left[\mathrm{Ca}^{2+}\right]_{\mathrm{i}}$, which was further enhanced after $24 \mathrm{~h}$ of A $\beta_{1-42}$ exposure (Figs. $4 D, 5 D$ ).

On the other hand, $5 \mu \mathrm{M} \mathrm{A} \beta_{1-42}$ induced an increase in SBFImonitored intracellular $\mathrm{Na}^{+}$levels at 6 and $18 \mathrm{~h}$ in NGFdifferentiated PC12 cells (Fig. 4E).

Effect of NCX3 silencing on caspase-12 activation, neuronal death and nuclear morphology induced by $A \beta_{1-42}$

In neuronal cells, $A \beta_{1-42}$ caused at $72 \mathrm{~h}$ the activation of caspase12, a specific marker of ER stress (Fig. 6A) and cell death, as revealed by measuring the ratio between dead and living cells (PI/FDA+PI ratio) (Fig. 6C). Interestingly, in these cells, when NCX3 was silenced, $A \beta_{1-42}$-induced caspase- 12 activation, and cell death occurred $48 \mathrm{~h}$ earlier (Fig. $6 \mathrm{~B}, C$ ). In addition, silencing of NCX3 hastened $A \beta_{1-42}$-induced abnormal nuclear morphology at $72 \mathrm{~h}$, as detected by Hoechst 33258 (data not shown).

\section{Molecular determinants of $\mathrm{A}_{1-42}$-induced increase in NCX3 activity}

To investigate the molecular determinants of calpain-dependent effects of $\mathrm{A} \beta_{1-42}$ on NCX3 activity, the NCX3 cDNA was stably transfected in BHK cells, which do not constitutively express NCX isoforms. Similar to neuronal cells, BHK-NCX3 cells exposed to $5 \mu \mathrm{MA} \beta_{1-42}$ exhibited increased $\left[\mathrm{Ca}^{2+}\right]_{\mathrm{i}}$ levels (Fig. $7 A$ ), calpain activation (Fig. 7B), NCX3 cleavage (Fig. 7C), and increased $\mathrm{I}_{\mathrm{NCX}}$ in the reverse mode of operation (Fig. $7 D$ ). Thereafter, a deletion mutant of NCX3, two NCX3/NCX1 chimeras, and a site-directed NCX3 mutant were generated to identify the amino acids involved in the $A \beta_{1-42}$-induced upregulation of $\mathrm{I}_{\mathrm{NCX}}$. In particular, deletion mutagenesis of NCX3 f-loop $(\mathrm{NCX} 3 \Delta \mathrm{f})$ was made to remove calpain cleavage sites. In this mutant, as well as in BHK-NCX1 and BHK-NCX2, A $\beta_{1-42}$ failed to increase $\mathrm{I}_{\mathrm{NCX}}$ in the reverse mode of operation (Fig. $8 A$ ). To further characterize the region of the NCX3 $\mathrm{f}$-loop involved in the $\mathrm{A} \beta_{1-42}$-induced effect, we generated two NCX3/NCX1 chimeras, $\mathrm{NCX}_{\text {NCX1TM5 }}$ and NCX3 $3_{\text {NCX1TM6}}$. Both NCX3/NCX1 chimeras and $\mathrm{NCX} 3 \Delta \mathrm{f}$ mutant were able to generate $\mathrm{I}_{\mathrm{NCX}}$ similar to those carried by wild-type NCX1 and NCX3 (data now shown). The $\mathrm{NCX}_{\text {NCX1TM5 }}$ chimera, obtained by substituting the transmembrane segment TM5 and a part of the f-loop (227-469) of NCX3 with the homologous region of NCX1, was not cleaved by calpain and did not show an enhancement of its activity following $\mathrm{A} \beta_{1-42}$ exposure (Fig. $8 A, B$ ). By contrast, $\mathrm{NCX}_{\mathrm{NCX}_{\mathrm{TM}} 6}$ chimera, obtained by substituting the transmembrane segment TM6 and part of the floop (707-776) of NCX3 with the homologous region of NCX1, was cleaved by calpain and showed an enhanced activity following $\mathrm{A} \beta_{1-42}$ exposure (Fig. $8 \mathrm{~A}, \mathrm{C}$ ). Finally, the double substitution of Lys371 and Lys372 with two tryptophan residues in NCX3 $\left(\mathrm{NCX}_{\mathrm{KK} / \mathrm{Ww}}\right)$ prevented calpain-induced NCX3 cleavage (Fig. $9 A, B$ ) and $\mathrm{A} \beta_{1-42}$-induced enhancement of $\mathrm{NCX} 3$ activity in the reverse mode of operation (Fig. 9C).

\section{Discussion}

The results of the present study demonstrated for the first time that, in neurons, $\mathrm{A} \beta_{1-42}$ induced a concentration-dependent in-
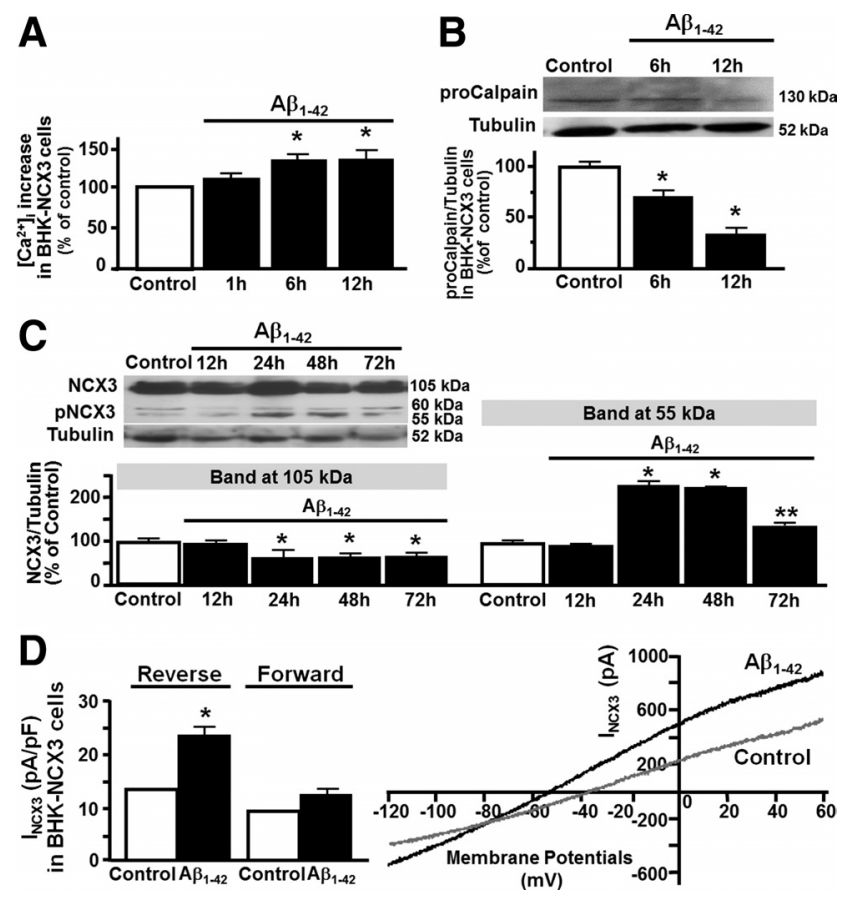

Figure 7. Effect of $A \beta_{1-42}$ on calpain activation and formation of $N C X 3$ proteolytic fragment in stably transfected BHK-NCX3 cells. $A$, Quantification of the time-dependent effect of $5 \mu \mathrm{m}$ $A \beta_{1-42}$ on $\left[\mathrm{Ca}^{2+}\right]_{\mathrm{i}}$. Values are expressed as percentage mean \pm SEM of 3 independent experimental sessions ( $n=40$ for each experimental group). $\boldsymbol{B}$, Representative Western blot and densitometric quantification of calpain activation under control conditions and after 6 and $12 \mathrm{~h}$ of $A \beta_{1-42}$ exposure. Values are expressed as percentage mean \pm SEM of 4 independent experimental sections. $C$, Representative Western blot and densitometric quantification of NCX3 protein expression and its proteolytic fragment under control conditions, after 12, 24, 48, and $72 \mathrm{~h}$ of $5 \mu \mathrm{MA} \beta_{1-42}$ exposure. Values are expressed as percentage mean \pm SEM of 7 independent experimental sections. $\boldsymbol{D}$, Representative superimposed traces and quantification of $\mathrm{I}_{\mathrm{NCX} 3}$ recorded under control conditions (gray trace) and after $5 \mu \mathrm{m} \mathrm{A} \beta_{1-42}$ exposure for $24 \mathrm{~h}$ (black trace). Values are expressed as mean \pm SEM of 3 independent experimental sessions ( $n=20$ for each group). ${ }^{*} p<0.05$ versus respective controls; ${ }^{* *} p<0.05$ versus 24 and $48 \mathrm{~h}$ of $A \beta_{1-42}$ exposure.

crease in $\mathrm{I}_{\mathrm{NCX}}$ in the reverse mode of operation and that this enhancement was mediated by NCX3 but not by NCX1 and NCX2 isoforms. Indeed, this augmented activity was due to the increased formation of NCX3 hyperfunctional proteolytic fragment induced by $\mathrm{Ca}^{2+}$-dependent calpain activation. In fact, the removal of the consensus site for calpain cleavage located on the f-loop prevented the formation of the proteolytic fragment and abolished the $\mathrm{A} \beta_{1-42}$ stimulatory effect on $\mathrm{I}_{\mathrm{NCX}}$. Moreover, generation of the proteolytic fragment contributed to increasing $\mathrm{Ca}^{2+}$ content in ER, thus delaying ER stress. Formation of the NCX3 hyperfunctional proteolytic fragment may represent an initial defense mechanism against $\mathrm{A} \beta_{1-42}$-insult for it could help neurons to delay ER stress, caspase-12 activation, and, eventually, neuronal death. By contrast, in the late phase $(72 \mathrm{~h})$, when the NCX3 proteolytic cleavage abruptly ceased, a parallel reduction in ER $\mathrm{Ca}^{2+}$ content occurred, thus triggering ER stress, as revealed by the activation of caspase- 12 and by an increase in neuronal death.

It is well known that $\mathrm{A} \beta_{1-42}$-exposure induces an increase in $\left[\mathrm{Ca}^{2+}\right]_{\mathrm{i}}$ through several mechanisms, including VDCCs $\mathrm{A} \beta$ oligomers-dependent pores (Berridge, 2010; Demuro et al., 2011), and nicotinic (Chin et al., 2006), NMDA, and AMPA receptors (Alberdi et al., 2010; Berridge, 2010). The $A \beta_{1-42}$-induced early increase in $\left[\mathrm{Ca}^{2+}\right]_{i}$ depends on the entrance of the ion from the extracellular compartment since its external removal prevents this early increase 
A NCX $3_{W T}$ Calpain
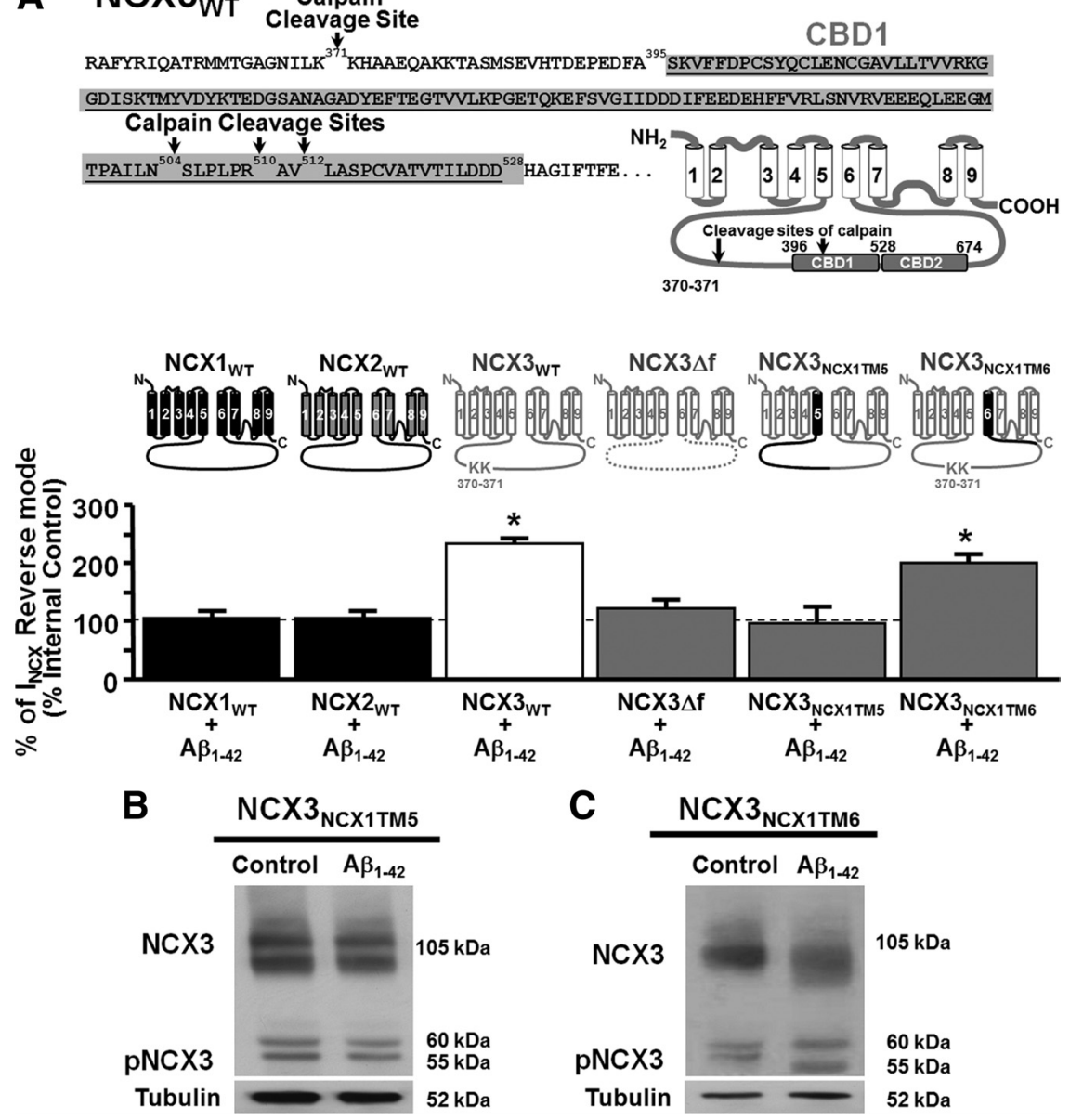

Figure 8. Effects of $A \beta_{1-42}$ on $I_{N C X}$ in BHK cells stably transfected with $N C X 3$ mutants and chimeras. $A, N C X 3$ sequence containing the calpain cleavage sites (top) and quantification of the $5 \mu \mathrm{mA} \beta_{1-42}$ effect on $I_{N C X}$ recorded in BHK cells transfected with $\mathrm{NCX} 1, \mathrm{NCX} 2$, or NCX3 and each single chimera and mutant (bottom). Values are expressed as percentage mean \pm SEM of 3 independent experimental sections ( $n=15$ for each group). ${ }^{*} p<0.05$ versus respective controls. $\boldsymbol{B}$, Representative Western blot of $\mathrm{NCX}_{\mathrm{NCX} 1 \mathrm{TM} 5}$ expression under control conditions and after $5 \mu \mathrm{MA} \beta_{1-42}$ exposure for $24 \mathrm{~h}$. C, Representative Western blot of $\mathrm{NCX} 3_{\mathrm{NCX1TM6}}$ expression under control conditions and after $5 \mu \mathrm{MA} \beta_{1-42}$ exposure for $24 \mathrm{~h}$.

(Pannaccione et al., 2005). In addition, NCX3 was not involved in the early $\left[\mathrm{Ca}^{2+}\right]_{\mathrm{i}}$ increase given that NCX3 silencing did not prevent this rise. Interestingly, the $\mathrm{A} \beta_{1-42}$-induced increase in $\left[\mathrm{Ca}^{2+}\right]_{\mathrm{i}}$, occurring at $30 \mathrm{~min}$, was followed by calpain activation, which was seen at $1 \mathrm{~h}$ and lasted for $12 \mathrm{~h}$. Intriguingly, a similar activation has also been found in human samples during $\mathrm{AD}$ and other neurodegenerative diseases (Vosler et al., 2008). Calpain activation, in turn, led to the formation of the NCX3 proteolytic fragment that appeared at $12 \mathrm{~h}$ and lasted up to $48 \mathrm{~h}$. In fact, the NCX3 sequence contains, at the level of the f-loop, two calpain cleavage sites (Bano et al., 2005). In the present study, we found that the two lysine residues (370-371) in the f-loop of the NCX3 sequence may represent the molecular determinants of calpain cleavage and are therefore responsible for the $\mathrm{A} \beta_{1-42}$ stimulatory effect on NCX3. In fact, when the two lysines were replaced with two tryptophan residues that are not recognized by calpain (Tompa et al., 2004), the formation of the hyperfunctional proteolytic fragment was prevented. Interestingly, hyperfunctional activity of the NCX3 antiporter, elicited by calpain cleavage, is reminiscent of the results obtained by Philipson's group with the other isoform, NCX1 (Matsuoka et al., 1993). Indeed, these authors found that after $\alpha$-chemotrypsin-mediated cleavage, NCX1 becomes hyperfunctional because it loses its inhibitory regulation present in the f-loop.
Since NCX activity and its modes of operation are regulated not only by $\left[\mathrm{Ca}^{2+}\right]_{\mathrm{i}}$ but also by $\left[\mathrm{Na}^{+}\right]_{\mathrm{i}}$, the concentration of this ion was determined. We found that $\left[\mathrm{Na}^{+}\right]_{\mathrm{i}}$ increased at 6 and $18 \mathrm{~h}$ after $\mathrm{A} \beta_{1-42}$ exposure, thus favoring the activity of NCX in the reverse mode of operation (Blaustein and Lederer, 1999; Philipson and Nicoll, 2000; Annunziato et al., 2004). The increase in $\left[\mathrm{Na}^{+}\right]_{\mathrm{i}}$ during $\mathrm{A} \beta_{1-42}$ exposure can be explained by the results of Mattson's group (Mark et al., 1995) showing that $\mathrm{A} \beta$ fragments inhibit the $\mathrm{Na}^{+} / \mathrm{K}^{+}$pump, one of the major mechanisms involved in $\mathrm{Na}^{+}$extrusion. In accordance with these findings, it has been shown that in synaptosomes obtained from the brains of patients affected by $\mathrm{AD}$, the activity of the $\mathrm{Na}^{+} / \mathrm{K}^{+}$ATPase is markedly reduced (Chauhan et al., 1997; Hattori et al., 1998). On the other hand, it should be underscored that $\mathrm{A} \beta_{1-42}$ can induce potential changes in $\mathrm{Na}^{+}$influx pathways. In fact, the $\beta$-amyloid peptide can induce membrane depolarization by increasing $\mathrm{Na}^{+}$influx though the activation of TTX-sensitive $\mathrm{Na}^{+}$channels (Mukhamedyarov et al., 2009).

More relevantly, the increased activity of the NCX3 proteolytic fragment may intervene in the ER-refilling dysregulation observed in $\mathrm{AD}$. In fact, $\mathrm{A} \beta_{1-42}$ also induces ER dysregulation in other neuronal models of degeneration (Verkhratsky and Toescu, 2003). Particularly, ER seems to play a crucial role in $\mathrm{AD}$ pathogenesis (Guo et al., 1996; Supnet et al., 2006; Bezprozvanny and Mattson, 2008) because it is an important site for generating $\mathrm{A} \beta$ fragments in neurons and, because presenilin-1 and -2 proteins are both predominantly localized in this cellular compartment (Walter et al., 1996). Interestingly, $\mathrm{Ca}^{2+}$ refilling into ER seems to be a crucial early self-protective mechanism against ER stress (Verkhratsky and Toescu, 2003). In the present study, our results indicated that there exists both a temporal and a functional relationship between $\mathrm{NCX} 3$ and $\mathrm{Ca}^{2+}$ buffering into ER. Indeed, when NCX3 was silenced or knocked-out, the larger $\mathrm{A} \beta_{1-42}$-induced ER$\mathrm{Ca}^{2+}$ accumulation was prevented and ER stress, $\left[\mathrm{Ca}^{2+}\right]_{\mathrm{i}}$ increase, and cell death prematurely occurred, thus demonstrating the beneficial contribution of NCX3 to the ER-refilling process. In accordance with these results, in anoxic astrocytes (Lenart et al., 2004) and in $\mathrm{Ca}^{2+}$ oscillating muscle cells, NCX blockade prevents ER $\mathrm{Ca}^{2+}$. refilling (Fameli et al., 2007). Similarly, during OGD, the other isoform, NCX1 is upregulated in the reverse mode of operation and plays a fundamental role in the $\mathrm{Ca}^{2+}$-refilling process, thus helping neurons to prevent ER stress (Sirabella et al., 2009). Likewise, we found that increases in NCX3 activity observed after 24 and 48 h of exposure seemed to delay ER stress, caspase- 12 activation, and neuronal death triggered by $\mathrm{A} \beta_{1-42}$. By contrast, in the late phase, at $72 \mathrm{~h}$, when the NCX3 proteolytic fragment abruptly decreased, the effect of $\mathrm{A} \beta_{1-42}$ switched from a protective signal to a cell death one. In fact, $\mathrm{A} \beta_{1-42}$ caused a depletion of the $\mathrm{Ca}^{2+}$ content in ER and an increase in $\left[\mathrm{Ca}^{2+}\right]_{\mathrm{i}}$ thus triggering ER stress, as evidenced by 
caspase- 12 activation, and, ultimately, neuronal death. On the other hand, several lines of evidence have indicated that NCX3 also plays a protective role under anoxic and ischemic conditions (Condrescu et al., 1995; Linck et al., 1998; Pignataro et al., 2004; Gomez-Villafuertes et al., 2005; Boscia et al., 2006; Secondo et al., 2007; Molinaro et al., 2008).

In another study, Nicotera's group (Bano et al., 2005) showed that during brain ischemia and glutamate exposure, NCX3 can be cleaved by the $\mathrm{Ca}^{2+}$-activated calpain, thus producing similar proteolytic fragments. However, this mechanism has been interpreted as a destruction of the cellular defenses following stroke (Choi, 2005). By contrast, in our study, we demonstrated that this cleavage produced a hyperfunctional NCX3 proteolytic fragment that exerted a protective effect during the first $48 \mathrm{~h}$ of $\mathrm{A} \beta_{1-42}$ exposure. On the other hand, Colvin et al. (1994) already observed an increase in NCX activity in plasma membrane vesicles from human postmortem tissues of the frontal cortex, temporal cortex, and cerebellum of $\mathrm{AD}$ patients and hypothesized that the increased NCX activity could exert, in the early phase of the disease, a neuroprotective role in $\mathrm{AD}$ through a correction of intracellular calcium dysregulation.

Together, these data suggest that $\mathrm{A} \beta_{1-42^{-}}$ induced upregulation of NCX3 activity may contribute to $\mathrm{ER}^{2}{ }^{2+}$ refilling during $\mathrm{A} \beta_{1-42}$ insult, thus helping neurons to mitigate ER stress and thus delaying neuronal death. Although these results may appear as a paradox considering $\mathrm{A} \beta_{1-42}$ neurotoxicity, they might be interpreted as a survival strategy activated by neurons in an attempt to defend themselves from the death messages triggered by this peptide during the early phase of exposure.

Finally, even if drugs selectively activating NCX3 are in development and not yet available, this molecular target might be of clinical relevance and open a new, additional strategy against $\mathrm{AD}$.

\section{References}

Alberdi E, Sánchez-Gómez MV, Cavaliere F, Pérez-Samartín A, Zugaza JL, Trullas R, Domercq M, Matute C (2010) Amyloid beta oligomers induce $\mathrm{Ca} 2+$ dysregulation and neuronal death through activation of ionotropic glutamate receptors. Cell Calcium 47:264-272.

Annunziato L, Pignataro G, Di Renzo GF (2004) Pharmacology of brain $\mathrm{Na}+/ \mathrm{Ca} 2+$ exchanger: from molecular biology to therapeutic perspectives. Pharmacol Rev 56:633-654.

Bano D, Young KW, Guerin CJ, Lefeuvre R, Rothwell NJ, Naldini L, Rizzuto R, Carafoli E, Nicotera P (2005) Cleavage of the plasma membrane $\mathrm{Na}+/ \mathrm{Ca} 2+$ exchanger in excitotoxicity. Cell 120:275-285.

Berridge MJ (2010) Calcium hypothesis of Alzheimer's disease. Pflugers Arch 459:441-449.

Bezprozvanny I, Mattson MP (2008) Neuronal calcium mishandling and the pathogenesis of Alzheimer's disease. Trends Neurosci 31:454-463.

Blaustein MP, Lederer WJ (1999) Sodium/calcium exchange: its physiological implications. Physiol Rev 79:763-854.
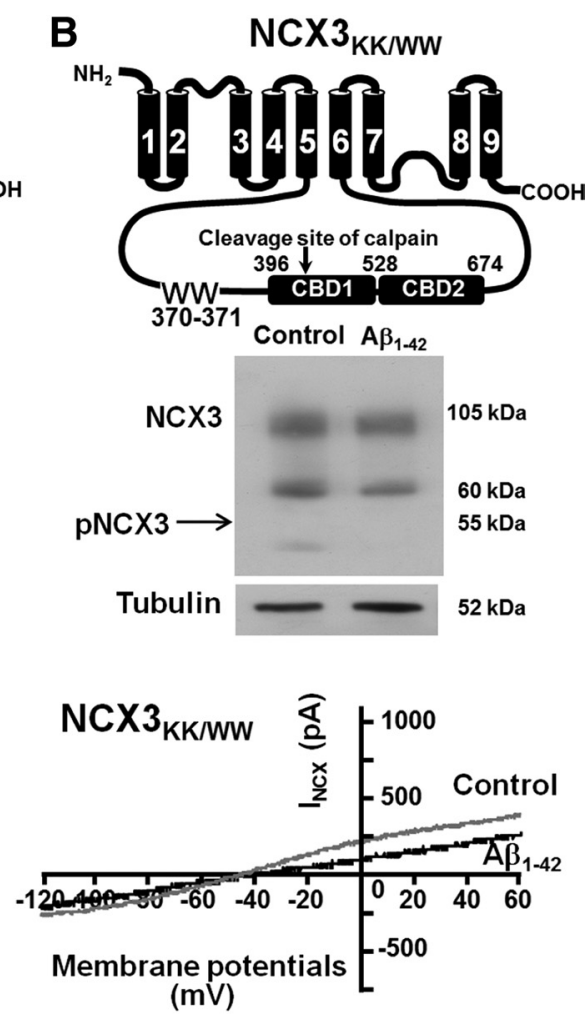

Figure 9. Effects of $\mathrm{A} \beta_{1-42}$ on $\mathrm{I}_{\mathrm{NCX} 3}$ in $\mathrm{BHK}$ cells stably transfected with $\mathrm{NCX}{ }_{\mathrm{KK} / \mathrm{wW}} \cdot \boldsymbol{A}, \boldsymbol{B}$, Representative Western blots of $\mathrm{NCX} 3$ trace) and after $24 \mathrm{~h}$ of $5 \mu \mathrm{mA} \beta_{1-42}$ exposure (black trace). Values are expressed as percentage mean \pm SEM of 3 independent experimental sections $(n=16) .{ }^{*} p<0.05$ versus respective untreated control and all other groups.

Boscia F, Gala R, Pignataro G, de Bartolomeis A, Cicale M, AmbesiImpiombato A, Di Renzo G, Annunziato L (2006) Permanent focal brain ischemia induces isoform-dependent changes in the pattern of $\mathrm{Na}+/ \mathrm{Ca} 2+$ exchanger gene expression in the ischemic core, periinfarct area, and intact brain regions. J Cereb Blood Flow Metab 26:502-517.

Chakroborty S, Goussakov I, Miller MB, Stutzmann GE (2009) Deviant ryanodine receptor-mediated calcium release resets synaptic homeostasis in presymptomatic 3xTg-AD mice. J Neurosci 29:9458-9470.

Chauhan NB, Lee JM, Siegel GJ (1997) Na,K-ATPase mRNA levels and plaque load in Alzheimer's disease. J Mol Neurosci 9:151-166.

Chin JH, Tse FW, Harris K, Jhamandas JH (2006) Beta-amyloid enhances intracellular calcium rises mediated by repeated activation of intracellular calcium stores and nicotinic receptors in acutely dissociated rat basal forebrain neurons. Brain Cell Biol 35:173-186.

Choi DW (2005) Neurodegeneration: cellular defences destroyed. Nature 433:696-698.

Colvin RA, Davis N, Wu A, Murphy CA, Levengood J (1994) Studies of the mechanism underlying increased $\mathrm{Na}+/ \mathrm{Ca} 2+$ exchange activity in Alzheimer's disease brain. Brain Res 665:192-200.

Condrescu M, Gardner JP, Chernaya G, Aceto JF, Kroupis C, Reeves JP (1995) ATP-dependent regulation of sodium-calcium exchange in Chi- 
nese hamster ovary cells transfected with the bovine cardiac sodiumcalcium exchanger. J Biol Chem 270:9137-9146.

Demuro A, Smith M, Parker I (2011) Single-channel Ca(2+) imaging implicates Abeta 1-42 amyloid pores in Alzheimer's disease pathology. J Cell Biol 195:515-524.

Fameli N, van Breemen C, Kuo KH (2007) A quantitative model for linking $\mathrm{Na}+/ \mathrm{Ca} 2+$ exchanger to SERCA during refilling of the sarcoplasmic reticulum to sustain $[\mathrm{Ca} 2+]$ oscillations in vascular smooth muscle. Cell Calcium 42:565-575.

Goll DE, Thompson VF, Li H, Wei W, Cong J (2003) The calpain system. Physiol Rev 83:731-801.

Gomez-Villafuertes R, Torres B, Barrio J, Savignac M, Gabellini N, Rizzato F, Pintado B, Gutierrez-Adan A, Mellström B, Carafoli E, Naranjo JR (2005) Downstream regulatory element antagonist modulator regulates $\mathrm{Ca}^{2+}$ homeostasis and viability in cerebellar neurons. J Neurosci 25:10822-10830.

Greene LA, Tischler AS (1976) Establishment of a noradrenergic clonal line of rat adrenal pheochromocytoma cells which respond to nerve growth factor. Proc Natl Acad Sci U S A 73:2424-2428.

Grynkiewicz G, Poenie M, Tsien RY (1985) A new generation of Ca2+ indicators with greatly improved fluorescence properties. J Biol Chem 260:3440-3450

Guo Q, Furukawa K, Sopher BL, Pham DG, Xie J, Robinson N, Martin GM, Mattson MP (1996) Alzheimer's PS-1 mutation perturbs calcium homeostasis and sensitizes PC12 cells to death induced by amyloid betapeptide. Neuroreport 8:379-383.

Hattori N, Kitagawa K, Higashida T, Yagyu K, Shimohama S, Wataya T, Perry G, Smith MA, Inagaki C (1998) CI-ATPase and $\mathrm{Na}+/ \mathrm{K}(+)$-ATPase activities in Alzheimer's disease brains. Neurosci Lett 254:141-144.

Iwamoto T, Pan Y, Nakamura TY, Wakabayashi S, Shigekawa M (1998) Protein kinase C-dependent regulation of $\mathrm{Na}+/ \mathrm{Ca} 2+$ exchanger isoforms NCX1 and NCX3 does not require their direct phosphorylation. Biochemistry 37:17230-17238.

Lee MS, Kwon YT, Li M, Peng J, Friedlander RM, Tsai LH (2000) Neurotoxicity induces cleavage of $\mathrm{p} 35$ to $\mathrm{p} 25$ by calpain. Nature 405:360-364.

Lenart B, Kintner DB, Shull GE, Sun D (2004) Na-K-Cl cotransportermediated intracellular $\mathrm{Na}^{+}$accumulation affects $\mathrm{Ca}^{2+}$ signaling in astrocytes in an in vitro ischemic model. J Neurosci 24:9585-9597.

Li Z, Matsuoka S, Hryshko LV, Nicoll DA, Bersohn MM, Burke EP, Lifton RP, Philipson KD (1994) Cloning of the NCX2 isoform of the plasma membrane $\mathrm{Na}(+)-\mathrm{Ca} 2+$ exchanger. J Biol Chem 269:17434-17439.

Linck B, Qiu Z, He Z, Tong Q, Hilgemann DW, Philipson KD (1998) Functional comparison of the three isoforms of the $\mathrm{Na}+/ \mathrm{Ca} 2+$ exchanger (NCX1, NCX2, NCX3). Am J Physiol 274:C415-C423.

Lorenzo A, Yankner BA (1994) Beta-amyloid neurotoxicity requires fibril formation and is inhibited by congo red. Proc Natl Acad Sci U S A 91:12243-12247.

Mark RJ, Hensley K, Butterfield DA, Mattson MP (1995) Amyloid betapeptide impairs ion-motive ATPase activities: evidence for a role in loss of neuronal $\mathrm{Ca}^{2+}$ homeostasis and cell death. J Neurosci 15:6239-6249.

Matsuoka S, Nicoll DA, Reilly RF, Hilgemann DW, Philipson KD (1993) Initial localization of regulatory regions of the cardiac sarcolemmal $\mathrm{Na}(+)-\mathrm{Ca} 2+$ exchanger. Proc Natl Acad Sci U S A 90:3870-3874.

Molinaro P, Cuomo O, Pignataro G, Boscia F, Sirabella R, Pannaccione A, Secondo A, Scorziello A, Adornetto A, Gala R, Viggiano D, Sokolow S, Herchuelz A, Schurmans S, Di Renzo G, Annunziato L (2008) Targeted disruption of $\mathrm{Na}^{+} / \mathrm{Ca}^{2+}$ exchanger 3 (NCX3) gene leads to a worsening of ischemic brain damage. J Neurosci 28:1179-1184.

Molinaro P, Viggiano D, Nisticò R, Sirabella R, Secondo A, Boscia F, Pannaccione A, Scorziello A, Mehdawy B, Sokolow S, Herchuelz A, Di Renzo GF, Annunziato L (2011) $\mathrm{Na}^{+}-\mathrm{Ca}^{2+}$ exchanger (NCX3) knock-out mice display an impairment in hippocampal long-term potentiation and spatial learning and memory. J Neurosci 31:7312-7321.

Morishima N, Nakanishi K, Takenouchi H, Shibata T, Yasuhiko Y (2002) An endoplasmic reticulum stress-specific caspase cascade in apoptosis: cytochrome $c$-independent activation of caspase- 9 by caspase-12. J Biol Chem 277:34287-34294.

Mukhamedyarov MA, Grishin SN, Yusupova ER, Zefirov AL, Palotás A (2009) Alzheimer's beta-amyloid-induced depolarization of skeletal muscle fibers: implications for motor dysfunctions in dementia. Cell Physiol Biochem 23:109-114.
Nicoll DA, Longoni S, Philipson KD (1990) Molecular cloning and functional expression of the cardiac sarcolemmal $\mathrm{Na}(+)-\mathrm{Ca} 2+$ exchanger. Science 250:562-565.

Nicoll DA, Quednau BD, Qui Z, Xia YR, Lusis AJ, Philipson KD (1996) Cloning of a third mammalian $\mathrm{Na}+-\mathrm{Ca} 2+$ exchanger, NCX3. J Biol Chem 271:24914-24921.

Pannaccione A, Secondo A, Scorziello A, Calì G, Taglialatela M, Annunziato L (2005) Nuclear factor-kappaB activation by reactive oxygen species mediates voltage-gated $\mathrm{K}+$ current enhancement by neurotoxic betaamyloid peptides in nerve growth factor-differentiated PC-12 cells and hippocampal neurones. J Neurochem 94:572-586.

Papa M, Canitano A, Boscia F, Castaldo P, Sellitti S, Porzig H, Taglialatela M, Annunziato L (2003) Differential expression of the $\mathrm{Na}+-\mathrm{Ca} 2+$ exchanger transcripts and proteins in rat brain regions. J Comp Neurol 461:31-48.

Paschen W (2003) Endoplasmic reticulum: a primary target in various acute disorders and degenerative diseases of the brain. Cell Calcium 34:365-383.

Philipson KD, Nicoll DA (2000) Sodium-calcium exchange: a molecular perspective. Annu Rev Physiol 62:111-133.

Pignataro G, Gala R, Cuomo O, Tortiglione A, Giaccio L, Castaldo P, Sirabella R, Matrone C, Canitano A, Amoroso S, Di Renzo G, Annunziato L (2004) Two sodium/calcium exchanger gene products, NCX1 and NCX3, play a major role in the development of permanent focal cerebral ischemia. Stroke 35:2566-2570.

Scalia R, Gong Y, Berzins B, Freund B, Feather D, Landesberg G, Mishra G (2011) A novel role for calpain in the endothelial dysfunction induced by activation of angiotensin II type 1 receptor signaling. Circ Res 108:1102-1111.

Scorziello A, Pellegrini C, Forte L, Tortiglione A, Gioielli A, Iossa S, Amoroso S, Tufano R, Di Renzo G, Annunziato L (2001) Differential vulnerability of cortical and cerebellar neurons in primary culture to oxygen glucose deprivation followed by reoxygenation. J Neurosci Res 63:20-26.

Secondo A, Staiano RI, Scorziello A, Sirabella R, Boscia F, Adornetto A, Valsecchi V, Molinaro P, Canzoniero LM, Di Renzo G, Annunziato L (2007) BHK cells transfected with NCX3 are more resistant to hypoxia followed by reoxygenation than those transfected with NCX1 and NCX2: possible relationship with mitochondrial membrane potential. Cell Calcium 42:521-535.

Secondo A, Pannaccione A, Molinaro P, Ambrosino P, Lippiello P, Esposito A, Cantile M, Khatri PR, Melisi D, Di Renzo G, Annunziato L (2009) Molecular pharmacology of the amiloride analog 3-amino-6-chloro-5[(4-chloro-benzyl)amino]-n-[[(2,4-dimethylbenzyl)-amino]iminomethyl]-pyrazinecarboxamide (CB-DMB) as a pan inhibitor of the $\mathrm{Na}+-\mathrm{Ca} 2+$ exchanger isoforms NCX1, NCX2, and NCX3 in stably transfected cells. J Pharmacol Exp Ther 331:212-221.

Selimovic D, Ahmad M, El-Khattouti A, Hannig M, Haïkel Y, Hassan M (2011) Apoptosis-related protein-2 triggers melanoma cell death by a mechanism including both endoplasmic reticulum stress and mitochondrial dysregulation. Carcinogenesis 32:1268-1278.

Sirabella R, Secondo A, Pannaccione A, Scorziello A, Valsecchi V, Adornetto A, Bilo L, Di Renzo G, Annunziato L (2009) Anoxia-induced NFkappaB-dependent upregulation of NCX1 contributes to Ca2 + refilling into endoplasmic reticulum in cortical neurons. Stroke 40:922-929.

Sokolow S, Luu SH, Headley AJ, Hanson AY, Kim T, Miller CA, Vinters HV, Gylys KH (2011) High levels of synaptosomal $\mathrm{Na}(+)-\mathrm{Ca}(2+)$ exchangers (NCX1, NCX2, NCX3) co-localized with amyloid-beta in human cerebral cortex affected by Alzheimer's disease. Cell Calcium 49:208-216.

Supnet C, Grant J, Kong H, Westaway D, Mayne M (2006) Amyloid-beta(1-42) increases ryanodine receptor-3 expression and function in neurons of TgCRND8 mice. J Biol Chem 281:38440-38447.

Tompa P, Buzder-Lantos P, Tantos A, Farkas A, Szilágyi A, Bánóczi Z, Hudecz F, Friedrich P (2004) On the sequential determinants of calpain cleavage. J Biol Chem 279:20775-20785.

Verkhratsky A, Toescu EC (2003) Endoplasmic reticulum Ca(2+) homeostasis and neuronal death. J Cell Mol Med 7:351-361.

Vosler PS, Brennan CS, Chen J (2008) Calpain-mediated signaling mechanisms in neuronal injury and neurodegeneration. Mol Neurobiol 38:78-100.

Walter J, Capell A, Grünberg J, Pesold B, Schindzielorz A, Prior R, Podlisny MB, Fraser P, Hyslop PS, Selkoe DJ, Haass C (1996) The Alzheimer's disease-associated presenilins are differentially phosphorylated proteins located predominantly within the endoplasmic reticulum. Mol Med 2:673-691. 